\title{
Variation of Genes Encoding Tryptophan Catabolites Pathway Enzymes in Stroke
}

\author{
Paulina Wigner ${ }^{1}$, Joanna Saluk-Bijak ${ }^{2}$, Ewelina Synowiec ${ }^{1}$, Elzbieta Miller ${ }^{3}{ }^{(D)}$, \\ Tomasz Sliwinski ${ }^{1}$ (D), Natalia Cichon ${ }^{2}$ and Michal Bijak ${ }^{2, * \mathbb{D}}$ \\ 1 Laboratory of Medical Genetics, Faculty of Biology and Environmental Protection, University of Lodz, \\ Pomorska 141/143, 90-236 Lodz, Poland; paulina.wigner@unilodz.eu (P.W.); \\ ewelina.synowiec@biol.uni.lodz.pl (E.S.); tomasz.sliwinski@biol.uni.lodz.pl (T.S.) \\ 2 Department of General Biochemistry, Faculty of Biology and Environmental Protection, University of Lodz, \\ Pomorska 141/143, 90-236 Lodz, Poland; joanna.saluk@biol.uni.lodz.pl (J.S.-B.); \\ natalia.cichon@biol.uni.lodz.pl (N.C.) \\ 3 Department of Neurological Rehabilitation, Medical University of Lodz, Poland, Milionowa 14, \\ 93-113 Lodz, Poland; elzbieta.dorota.miller@umed.lodz.pl \\ * Correspondence: michal.bijak@biol.uni.lodz.pl; Tel.: +48-42-635-43-36
}

Received: 10 November 2019; Accepted: 27 November 2019; Published: 3 December 2019

\begin{abstract}
The abnormal activation of the tryptophan catabolites pathway (TRYCATs) is observed in patients suffering from cerebrovascular disease, including stroke. A previous study confirmed that lower bioavailability of tryptophan for serotonin synthesis was characterized in the patients during the acute stroke phase. Interestingly, according to various studies, polymorphisms of the genes involved in the TRYCATs pathway may modulate the risk of stroke occurrence. Therefore, this study aimed to investigate the association between the occurrence of TPH1, TPH2, KAT1, KAT2 and IDO1 polymorphisms and the risk of stroke development.The following 10 polymorphisms of the genes encoding enzymes of the TRYCATs pathway were selected: c.804-7C > A (rs10488682), c. $-1668 \mathrm{~T}>\mathrm{A}(\mathrm{rs} 623580), \mathrm{c} .803+221 \mathrm{C}>\mathrm{A}(\mathrm{rs} 1800532), \mathrm{c} .-173 \mathrm{~A}>\mathrm{T}(\mathrm{rs} 1799913)-\mathrm{TPH} 1, \mathrm{c} .-1449 \mathrm{C}>\mathrm{A}$ (rs7963803), and c.-844G > T (rs4570625) - TPH2. c. ${ }^{* 456 G}>\mathrm{A}$ of KAT1 (rs10988134), c.975-7T > C of KAT2 (rs1480544), c.-1849C > A (rs3824259) and c. -1493G > C (rs10089084) of IDO1. The study was carried out on DNA isolated from the peripheral blood taken from 107 patients after a stroke and 107 healthy volunteers. All DNA samples were genotyped using TaqMan probes. The genotypes of eight studied polymorphisms modulated the risk of stroke. No significant difference in genotype and allele frequencies of the c.804-7C > A -TPH1 (rs10488682) and c. ${ }^{*} 456 \mathrm{G}>\mathrm{A}-\mathrm{KAT1}$ (rs10988134) polymorphisms were found between patients and controls. Having performed haplotype and gen-gen analyses, it was possible to determine that patients after a stroke and controls differed in terms of the frequency of selected genotypes and haplotypes. Among the studied polymorphisms, eight SNPs were linked with stroke risk modulation. The results obtained confirmed our hypothesis regarding the involvement of the TRYCATs pathway in the pathogenesis of stroke.
\end{abstract}

Keywords: stroke; TRYCATs; tryptophan; polymorphism

\section{Introduction}

Stroke is considered and classified as a cardiovascular disease, next to coronary artery diseases, heart failure, hypertensive heart disease, valvular heart disease, and carditis [1]. The World Health Organization defines stroke as a "neurological deficit of cerebrovascular cause that persists beyond $24 \mathrm{~h}$ or is interrupted by death within $24 \mathrm{~h}$ " [2]. There were 6.5 million stroke deaths in the world in 2013, making stroke the second-leading cause of death behind ischemic heart disease. Approximately 795,000 
strokes occur in the United States each year. Interestingly, someone has a stroke on average every $40 \mathrm{~s}$ in the United States, and someone dies of a stroke every 4 min [3]. There was an estimated number of 10.3 million new strokes in 2013, and $67 \%$ of them were ischemic strokes. Incidence for both ischemic and haemorrhagic strokes is higher among males than females [4]. Moreover, stroke is associated with high costs of treatment. It was estimated that the annual cost of treating CVD and strokes in the United States amounted to \$316.1 billion from 2012 to 2013 [3]. Studies conducted in recent years demonstrated that the tryptophan catabolites pathway (TRYCATs) might be associated with the prevalence of cardiovascular diseases, including stroke [5-7]. Moreover, the activation of the TRYCATs pathway was increased after a stroke and may be linked with stroke severity and poor prognosis $[7,8]$. So far, research findings suggest that patients after an ischemic stroke have a lowered concentration of tryptophan and kynurenine acid. Tryptophan is an amino acid which is also a precursor to the neurotransmitter serotonin and hormone melatonin, while kynurenine acid is its neuroprotective metabolite and an antagonist of the N-methyl-D-aspartate (NMDA) receptor $[9,10]$. Moreover, the kynurenine/tryptophan (KYN/TRP) ratio, meaning kynurenine transaminase (KAT) activity, was lower, while the kynurenic acid/kynurenine (KYNA/KYN) ratio, meaning indoleamine-2,3-dioxygenase IDO activity, was higher in patients when compared to healthy volunteers [11].

IDO is a rate-limiting enzyme, which initiates tryptophan metabolism through $\mathrm{O}_{2}$-dependent oxidation, whereas KAT catalyses irreversible transamination of kynurenine acid in the brain and peripheral tissues [12-14]. Furthermore, an animal-based study confirmed that ischemia, which is observed during a stroke, increased the expression of TDO as compared to control animals [15]. Interestingly, the TRYCATs pathway is closely linked with inflammatory modulation. IDO may be activated by pro-inflammatory cytokines, whereas anti-inflammatory cytokines may act as inhibitors of the enzyme [16,17]. Thus, an inflammatory response to an acute ischemic stroke may cause the activation of IDO and, consequently, may lead to tryptophan depletion and increased generation of kynurenine [18]. Additionally, previous findings suggest that Interleukin 10 (IL-10) may reduce the capability of 5-TH synthesis in the brain, which is observed in patients after a stroke [19,20].

Moreover, Ormstad et al. [21] revealed that high levels of interleukin $1 \beta$ are positively correlated with decreased bioavailability of TRP in the patients after an acute ischemic stroke. More details about the TRYCATs pathway were presented elsewhere [22]. The next study indicated that the activation of the kynurenine pathway plays a crucial role in the acute phase of a stroke as well as in fatigue and depression following a stroke. Patients with Fatigue Severity Scale (FSS) $\geq 4$ at 12 months post-stroke, were characterized by a reduced tryptophan (TRP) index as compared to patients with FSS $<4$ [21]. The index indicates the bioavailability of TRP in the plasma for serotonin (5-TH) synthesis in the brain [23]. Thus, the reduced TRP index confirmed lower bioavailability of TRP for 5-TH synthesis in patients during the acute stroke phase. Serotonin is important for wakefulness and inhibits rapid eye movement sleep [24]. Therefore, a low level of 5-TH synthesis may lead to abnormal tiredness and a need for long-lasting sleep [25].

In addition, an animal-based study showed that the level of kynurenine (a neurotoxic metabolite of tryptophan) during ischemia was increased in the brain [15]. Interestingly, kynurenine may activate an aryl hydrocarbon (Ah) receptor (ligand-activated transcription factor), and the activation is deleterious to cerebral ischemia. Accordingly, the study showed that the Ah receptor was overexpressed in the mouse brain after an experimental stroke, mainly in the neurons located at the peri-infarct and ischemic core. Similarly, increased expression of the Ah receptor was found in cultured rat cortical neurons after in vitro experimental ischemia [26]. Besides kynurenine, the level of another neurotoxic metabolite, i.e., quinolinic acid, was increased after transient ischemia in gerbils. This study was aimed to further elucidate the role of the TRYCATs pathway during a stroke in the Polish population. Therefore, single-nucleotide polymorphisms (SNPs) were investigated in the presented study. The studied SNPs were localized in the genes encoding the enzymes involved in the TRYCATs pathway, including tryptophan hydroxylase, kynurenine aminotransferase, and indoleamine 2,3-dioxygenase. Moreover, in this study, the further analysis included gen-gen interaction, haplotype and risk of stroke. 


\section{Materials and Methods}

\subsection{Subjects}

We recruited 107 patients with stroke and 107 age- and sex-matched control subjects (without stroke) in our case-control study. The case group comprised patients after an ischemic stroke hospitalized at the Neurorehabilitation Department of the 3rd General Hospital in Lodz, Poland, in the years 2015-2017. The cerebral ischemic event in each patient had been documented using computed tomography (CT) of the brain. Neurological and CT findings were interpreted by two or more independent and experienced neurologists. All the patients had been diagnosed with an ischemic stroke; we did not include patients having other types of strokes.

Among the selected individuals, the people with a history of cranial trauma, cerebral haemorrhage, atrial fibrillation, other major sources of cardioembolism, coagulation disorders, tumours, chronic inflammatory diseases, and autoimmune diseases were excluded from the study. Having excluded all such cases, 107 subjects (50 males and 57 females) with a clinically overt stroke were selected and classified into the study group. Paresis of the left part of the body was observed more frequently (68 vs. 39 ).

A complete medical history was collected for all the individuals enrolled in the study; the medical history included smoking habits, alcohol consumption, presence of diabetes, and drug treatment. Hypertension was defined as either (based on a mean value of three independent measures) systolic blood pressure $>140 \mathrm{~mm} \mathrm{Hg}$, diastolic pressure $>90 \mathrm{~mm} \mathrm{Hg}$, or current treatment using antihypertensive drugs. Hypercholesterolemia was defined as either a need for statins or total plasma cholesterol level $>200 \mathrm{mg} / \mathrm{L}$. Diabetes was diagnosed when a given subject had a fasting glucose level $>120 \mathrm{mg} / \mathrm{L}$.

The healthy volunteer's group included 107 healthy individuals with no history or prior diagnosis of any cardiovascular disease. The exclusion criteria were the same as those in the aforementioned study group. The controls were not related to the patients, and no history of stroke in their family members was confirmed.

All the patients were Caucasian and were recruited simultaneously from the same demographic area (central Poland). The full characteristics of the two groups are presented in Table 1.

All blood samples were collected in the morning (between 7 am and 9 am) in fasting status and stored using the same protocol. All procedures were done according to the Helsinki Declaration for Human Research and were approved by the Committee on the Ethics of Research in Human Experimentation at the University of Lodz with Resolution No. 28/2015. Informed consent was obtained from all participants and/or their legal guardians.

Table 1. Demographic and clinical data in patients with history of ischemic stroke and controls.

\begin{tabular}{cccc}
\hline & Patients $(\boldsymbol{n}=\mathbf{1 0 7})$ & Control $(\boldsymbol{n = 1 0 7 )}$ & $p$ \\
\hline Age & $50.1 \pm 11.8$ & $47.3 \pm 8.7$ & $0.049 *$ \\
\hline Gender (M/F) & $50 / 57$ & $53 / 54$ & 0.7844 \\
\hline Hypertension & 83 & 54 & 0.0001 \\
\hline Hypercholesterolemia & 77 & 52 & 0.0008 \\
\hline Diabetes & 36 & 24 & 0.0941 \\
\hline Smoking (current) & 37 & 35 & 0.8850 \\
\hline Smoking (former) & 20 & 20 & 0.8608 \\
\hline Daily alcohol consumption & 27 & 23 & 0.6279 \\
\hline
\end{tabular}

$p$ - values for a two-sided $\chi^{2}$ - test; except for * for $t$-test. 


\subsection{Selection of Single-Nucleotide Polymorphisms}

All studied polymorphisms were chosen using the Database of Single Nucleotide Polymorphisms (dbSNP) of the National Center for Biotechnology Information (NCBI) available at http://www.ncbi. nlm.nih.gov/snp (Bethesda, MD, USA).

Our searches were conducted based on the following criteria:

1. a minor allele frequency of 0.05 or greater in the European population

2. location at the regulatory region of genes, i.e., the $5^{\prime}$ near a gene, the $5^{\prime}$ UTR, the $3^{\prime}$ UTR and intron. All studied polymorphisms are presented in Table 2.

Table 2. Characteristics of studied single-nucleotide polymorphisms (SNPs).

\begin{tabular}{|c|c|c|c|}
\hline Gene & rs Number & Polymorphism & Localization \\
\hline \multirow{4}{*}{ TPH1 } & rs1799913 & c. $804-7 C>A$ & intron \\
\hline & rs623580 & c. $-1668 \mathrm{~T}>\mathrm{A}$ & near gene $5^{\prime}$ \\
\hline & rs1800532 & c. $803+221 C>A$ & intron \\
\hline & rs10488682 & c. $-173 \mathrm{~A}>\mathrm{T}$ & near gene $5^{\prime}$ \\
\hline \multirow{2}{*}{ TPH2 } & rs7963803 & c. $-1449 \mathrm{C}>\mathrm{A}$ & \multirow{2}{*}{ near gene $5^{\prime}$} \\
\hline & rs4570625 & c. $-844 \mathrm{G}>\mathrm{T}$ & \\
\hline KAT 1 & rs10988134 & c. ${ }^{4} 456 \mathrm{G}>\mathrm{A}$ & UTR-3' \\
\hline KAT 2 & rs1480544 & c. $975-7 \mathrm{~T}>\mathrm{C}$ & intron \\
\hline \multirow{2}{*}{ IDO 1} & rs3824259 & c. $-1849 \mathrm{C}>\mathrm{A}$ & \multirow{2}{*}{ near gene $5^{\prime}$} \\
\hline & rs10089084 & c. $-1493 G>C$ & \\
\hline
\end{tabular}

\subsection{DNA Isolation}

Genomic DNA was extracted from venous blood according to the SaMag ${ }^{\mathrm{TM}}$ Blood DNA Extraction Kit protocol and using the commercially available SaMag ${ }^{\text {TM }}$ System (Sacace Biotechnologies S.r.l., Vicenza, Como, Italy). Then, the concentration and purity of DNA samples were determined by a spectrophotometer, where a 260/280 $\mathrm{nm}$ optical density (OD) ratio in range 1.8-2.0 was considered high quality and stored at $-20^{\circ} \mathrm{C}$ until use. the Genotyping.

During our study, we investigated 10 SNPs of the genes encoding enzymes of the TRYCATs pathway. TaqMan ${ }^{\circledR}$ SNP Genotyping Assays (Thermo Fisher Scientific, Waltham, Massachusetts, USA) and TaqMan ${ }^{\mathrm{TM}}$ Universal Master Mix II, no UNG (Thermo Fisher Scientific, Waltham, Massachusetts, USA) were used to perform the genotyping of the selected SNPs. The Taq-Man Assay IDs are presented in Table 3. The thermal cycling conditions were as follows: initial denaturing at $95^{\circ} \mathrm{C}$ for $10 \mathrm{~min}$, 40 cycles of $92{ }^{\circ} \mathrm{C}$ for $15 \mathrm{sec}$ and $60^{\circ} \mathrm{C}$ for $60 \mathrm{sec}$. All reactions were carried out in a thermal cycler CFX96 ${ }^{\mathrm{TM}}$ Real-Time Polymerase Chain Reaction (PCR) Detection System (BIO-RAD). The genotypes were determined automatically based on dye-component fluorescent emission data depicted in the X-Y scatter-plot of the CFX Manager TM Software (version 3.1- BIO-RAD, Hercules, California, USA). The Figure 1 shows a representative allelic discrimination X-Y scatter-plot of the c.804-7C >A SNP (rs1799913) of the TPH1 gene. 
Table 3. Details of TaqMan ${ }^{\circledR}$ SNP genotyping assays used in this study.

\begin{tabular}{ccc}
\hline Polymorphism & Assay ID & Location \\
\hline rs1799913 & C__2645661_10 & Chr.11: 18,025,708 on GRCh38 \\
\hline rs623580 & C__2645676_10 & Chr.11: 18,042,430 on GRCh38 \\
\hline rs1800532 & C__8940793_10 & Chr.11: 18,026,269 on GRCh38 \\
\hline rs10488682 & C__2645675_10 & Chr.11: 18,040,935 on GRCh38 \\
\hline rs7963803 & C__27855793_30 & Chr.12: 71,937,538 on GRCh38 \\
\hline rs4570625 & C__226207_10 & Chr.12: 71,938,143 on GRCh38 \\
\hline rs10988134 & C__11840549_10 & Chr.9: $128,833,128$ on GRCh38 \\
\hline rs1480544 & C__8242555_10 & Chr.4: 170,066,485 on GRCh38 \\
\hline rs3824259 & C__27491530_10 & Chr.8: 39,912,074 on GRCh38 \\
\hline rs10089084 & C_30475151_10 & Chr.8: 39,912,430 on GRCh38 \\
\hline
\end{tabular}

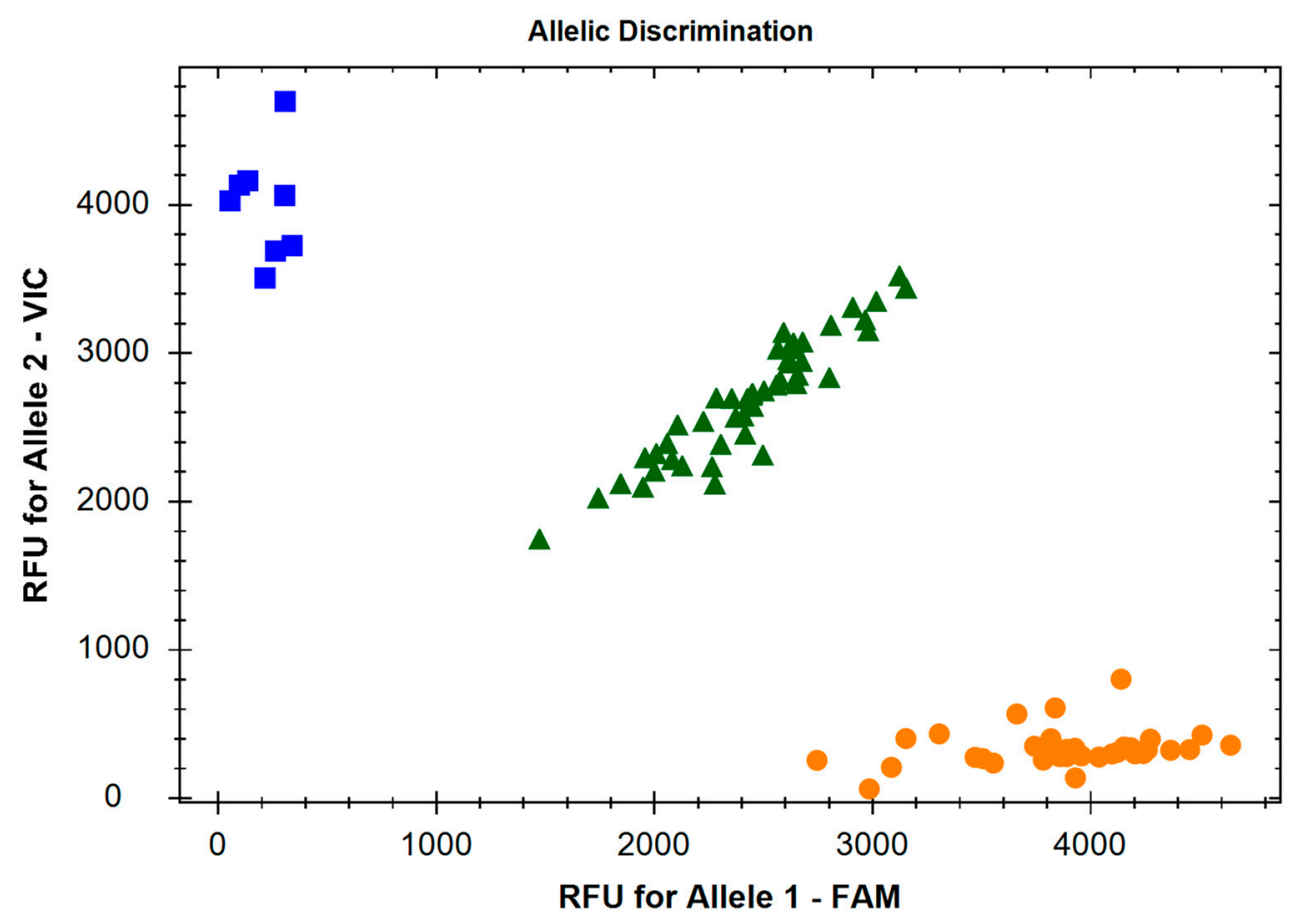

Figure 1. Allelic discrimination X-Y scatter-plot of the c.804-7C>A SNP (rs1799913) of the TPH1 gene. The TaqMan ${ }^{\circledR}$ SNP Genotyping Assay (ID: C__2645661_10) was used for genotyping of this SNP. The $\chi$-axis represents the relative fluorescent emission for the A allele-specific probe labelled with 6-carboxyfluorescein (FAM), and the $V$-axis represents the emission for the $C$ allele-specific probe labelled with 2'-chloro-7'-phenyl-1,4-dichloro-6-carboxyfluorescein (VIC). Circles: homozygous A/A; squares: homozygous $\mathrm{C} / \mathrm{C}$; triangles: heterozygous $\mathrm{C} / \mathrm{A}$.

\subsection{Statistical Analysis}

A statistical analysis of the results was performed in Statistica, version 12 for Windows (Statsoft, Tulsa, OK, USA), and SigmaPlot, version 11.0 for Windows (Systat Software Inc., San Jose, CA, USA). Calculations of the association between case/control and each studied polymorphism were performed in accordance with the unconditional multiple logistic regression model. The odds ratios (ORs) with 95\% confidence interval (95\% CI) served to assess the strength of association. Haplotypic frequencies were estimated using MedCalc software, version 15.0 for Windows (Ostend, Belgium). The values of $p<0.05$ were considered statistically significant. 


\section{Results}

3.1. Single Nucleotide Polymorphisms of the Genes Encoding TRYCATs Enzymes (TPH1, TPH2, KAT1, KAT2 and IDO1) as the Risk of Stroke Occurrence

Among the studied SNPs (Table 4), the heterozygote and the C allele of c.804-7C > A - TPH1 (rs1799913) were associated with a reduced risk of stroke occurrence, and the homozygote A/A and the A allele of the same SNP decreased this risk. A statistical analysis of disturbances in the genotypes and alleles of the $\mathrm{c} .803+221 \mathrm{C}>\mathrm{A}-\mathrm{TPH} 1$ (rs1800532) polymorphism confirmed that the C/C and A/A homozygotes were linked with an increased frequency of stroke occurrence by 20 times, while the heterozygote of the same SNP showed a protective character and reduced the risk. The results demonstrated that the T/T genotype and T allele of c.-1668T > A - TPH1 (rs623580) were negatively correlated with stroke, whereas the A/A, T/A and A allele of the same polymorphism were positively correlated with the disease. Interestingly, the analysis of distribution of the genotypes and alleles of the c.-844G > T - TPH2 (rs4570625) polymorphism showed that the G/G homozygote and the G allele increased the risk of stroke by more than 30 times $(p<0.001)$, while the G/T genotype of the same SNP decreased the risk by nearly 27 times $(p<0.001)$. In case of c.-1449C > A - TPH2 (rs7963803), the C/C genotype and the $\mathrm{C}$ allele were positively correlated with stroke occurrence, whereas the heterozygote and the A allele protected against the onset of stroke. Additionally, the c.975-7T > C - KAT2 (rs1480544) polymorphism modulated the risk of stroke development. The $\mathrm{C} / \mathrm{C}$ genotype and the $\mathrm{C}$ allele of the SNP increased the risk of the disease, while the T/C and the $\mathrm{T}$ allele reduced the risk. Moreover, in the case of the c.-1493G > C - IDO1 (rs10089084) polymorphism, the G/G genotype and the G allele were linked with an increased frequency of stroke occurrence as compared to the control subjects, whereas the $\mathrm{C} / \mathrm{C}$ homozygote and the $\mathrm{C}$ allele reduced this risk. No correlation was found between genotypes/alleles of the c. $-173 \mathrm{~A}>\mathrm{T}-\mathrm{TPH} 1$ (rs10488682), c. ${ }^{* 456 \mathrm{G}}>\mathrm{A}-\mathrm{KAT} 1$ (rs10988134), c. $-1849 \mathrm{C}>$ A - IDO1 (rs3824259) polymorphisms and stroke development.

\subsection{Haplotypes and DD Prevalence}

Our team also investigated the correlation between the occurrence of stroke and haplotypes (Table S1) of the c.804-7C > A (rs1799913) and c.803+221C > A (rs1800532), c.804-7C > A (rs1799913) and c. $-173 \mathrm{~A}>\mathrm{T}(\mathrm{rs} 10488682), \mathrm{c} .804-7 \mathrm{C}>\mathrm{A}(\mathrm{rs} 1799913)$ and c. $-1668 \mathrm{~T}>\mathrm{A}(\mathrm{rs} 623580), \mathrm{c} .-173 \mathrm{~A}>\mathrm{T}(\mathrm{rs} 10488682)$ and c.803+221C > A (rs1800532), c. $-1668 \mathrm{~T}>\mathrm{A}(\mathrm{rs} 623580)$ and c.803+221C $>\mathrm{A}(\mathrm{rs} 1800532), \mathrm{c} .-173 \mathrm{~A}$ $>\mathrm{T}(\mathrm{rs} 10488682)$ and c.-1668T $>\mathrm{A}(\mathrm{rs623580})$ polymorphisms of the gene encoding TPH1, c.-1449C $>\mathrm{A}(\mathrm{rs} 7963803)$ and c.-844G $>\mathrm{T}$ (rs4570625) SNPs of the TPH2 gene, c.-1849C > A (rs3824259) and c. $-1493 \mathrm{G}>\mathrm{C}(\mathrm{rs10089084)}$ SNP of the IDO1 gene. In case of c.804-7C > A (rs1799913) and c.803+221C > A (rs1800532), haplotype AC decreased the risk of stroke by more than seventy-six times $(p<0.0001)$, while haplotype AA of the same SNPs combination only doubled this risk. Moreover, the CT haplotype of c.804-7C > A (rs1799913) and c.-173A > T (rs10488682) SNPs reduced the risk of stroke occurrence, whereas AT of the same combination of polymorphisms increased this risk. The obtained results showed that the TT and AT haplotypes of the c.804-7C > A (rs1799913) and c.-1668T > A (rs623580) polymorphisms were negatively correlated with stroke development, whereas the CA haplotype of the same combined SNPs increased the risk of the disease. Additionally, the AA haplotype of the c.-173A > $\mathrm{T}(\mathrm{rs} 10488682)$ and c.803+221C $>\mathrm{A}$ (rs1800532) combined SNPs reduced the frequency of stroke in the Polish population as compared to healthy volunteers. In the case of the c. $-1668 \mathrm{~T}>\mathrm{A}$ (rs623580) and c.803+221C > A (rs1800532) polymorphism, the TC haplotype was linked with the reduced risk of stroke development, while the AC haplotype of the same combination increased the frequency of stroke occurrence. Moreover, the AA and TA haplotypes of c.-173A > T (rs10488682) and c.-1668T > A (rs623580) were positively correlated with stroke, whereas the AT and TT haplotypes negatively correlated with the disease. In case of combined polymorphisms encoding TPH2 - i.e., c.-1449C > A (rs7963803) and c.-844G > T (rs4570625) - the CG increased the risk of stroke, while the CT, AG and AT haplotypes reduced this risk. Besides, the CG haplotype of c.-1849C > A (rs3824259) and c.-1493G > C 
(rs10089084) was linked with an increase in the risk of stroke occurrence, whereas the CC haplotype of the same SNPs combination reduced the risk.

\subsection{Gene-Gene Interactions and the Risk of Stroke}

We also investigated the correlation between stroke occurrence and combined genotypes of all the studied polymorphisms (Table S2). We found that the C/C-G/G combined genotype of the c.804-7C > A - TPH1 (rs1799913) and c.-844G > T - TPH2 (rs4570625) polymorphisms were associated with an increased risk of stroke. Interestingly, the presence of the C/A-G/T genotype of the same polymorphism combination reduced the risk of stroke development 100 times $(p<0.001)$, whereas the A/A-G/G combined polymorphisms elevated this risk more than 50 times $(p<0.001)$. There was a link between an increased risk of stroke and the frequency of the $\mathrm{C} / \mathrm{C}-\mathrm{C} / \mathrm{C}, \mathrm{A} / \mathrm{A}-\mathrm{C} / \mathrm{C}$ genotypes of c.804-7C > A - TPH1 (rs1799913) and c.-1449C > A - TPH2 (rs7963803), while the C/A-C/C and A/A-C/A genotypes reduced this risk. In the case of c.803 + 221C > A - TPH1 (rs1800532) and c.-844G > T TPH2 (rs4570625), the C/C-G/G and C/A-G/G were linked with the risk of stroke elevated by more than 10 times $(p<0.001)$. On the other hand, the $\mathrm{C} / \mathrm{A}-\mathrm{G} / \mathrm{T}$ genotypes of the same combined genotypes reduced this risk. Moreover, we observed that the $\mathrm{C} / \mathrm{C}-\mathrm{C} / \mathrm{C}$ combined genotype of the $\mathrm{c} .803+221 \mathrm{C}>$ A - TPH1 (rs1800532) and c.-1449C > A - TPH2 (rs7963803) polymorphisms were associated with an increased risk of stroke, whereas the C/A-C/A genotypes reduced the risk. Interestingly, the A/A-C/C genotypes of the same polymorphism combination increased the occurrence of stroke by more than 18 times $(p=0.005)$. The T/T-G/G and A/T-G/G genotypes of c.-173A $>\mathrm{T}-\mathrm{TPH} 1$ (rs10488682) and c.-844G $>$ T - TPH2 (rs4570625) SNPs caused an above 30-fold $(p<0.001)$ and a nearly 70-fold $(p<0.001)$ increase of the risk in the Polish population, respectively. However, the T/T-G/T and A/T-G/T genotypes of the same SNP combination were associated with a diminished risk of stroke occurrence. Moreover, we found that the T/T-C/C genotype of c.-173A > T - TPH1 (rs10488682) and c.-1449C > A - TPH2 (rs7963803) was linked with an elevated risk of stroke development, whereas the A/T-C/A genotype caused a decrease of this risk by nearly fifteen times. In the case of c.-1668T > A - TPH1 (rs623580) and c.-844G > T - TPH2 (rs4570625), combined genotypes T/T-G/G and T/A-G/G were associated with a more than 10-fold $(p<0.001)$ and eleven-fold $(p<0.001)$ increase of the DD risk, respectively. On the other hand, the T/T-G/T and T/A-G/T genotypes of the same combinations diminished the risk of the disease more than 20 -fold $(p<0.001)$ and more than twofold $(p=0.004)$, respectively Additionally, the presence of the T/T-C/C and T/A-C/A combined genotypes of the c.-1668T > A - TPH1 (rs623580) and c.-1449C > A - TPH2 (rs7963803) polymorphisms reduced the risk of stroke development, whereas the $\mathrm{T} / \mathrm{A}-\mathrm{C} / \mathrm{C}$ and $\mathrm{A} / \mathrm{A}-\mathrm{C} / \mathrm{C}$ genotypes were linked with an increased risk of the disease. Furthermore, we revealed that the G/G-C/A genotype of c. ${ }^{*} 456 \mathrm{G}>\mathrm{A}$ (rs10988134) - KAT1 and c. $-1849 \mathrm{C}>\mathrm{A}-\mathrm{IDO} 1$ (rs3824259) increased the risk of stroke. In addition, we observed that the C/C-C/A genotype of c.975-7T $>$ C- KAT2 (rs1480544) and- c.-1849C > A IDO1 (rs3824259) SNPs was associated with an increased risk of stroke. However, the T/C-C/A and T/C-A/A genotypes of the same combination caused an increase of stroke occurrence by more than 30 times $(p<0.001)$ and six times $(p=0.005)$, respectively. In the case of the c.-1493G > C - IDO1 (rs10089084) and c. ${ }^{*} 456 \mathrm{G}>\mathrm{A}-\mathrm{KAT1}$ (rs10988134) combined genotypes, we found that $\mathrm{G} / \mathrm{G}-\mathrm{G} / \mathrm{G}$ and $\mathrm{G} / \mathrm{G}-\mathrm{G} / \mathrm{A}$ were associated with a more than fourfold increase of the stroke risk, while the $\mathrm{C} / \mathrm{C}-\mathrm{G} / \mathrm{G}$ combined genotype of the same polymorphisms was associated with an increase of this risk by about 10 times $(p<0.001)$. The link between the reduced risk of stroke and the frequency of the G/G-T/C and G/A-T/C genotypes of the c. ${ }^{*} 456 \mathrm{G}>\mathrm{A}-\mathrm{KAT1}$ (rs10988134) and c.975-7T >C - KAT2 (rs1480544) polymorphisms were confirmed in our study. On the other hand, we found that the G/G-C/C and G/A-C/C genotypes of the same SNP combination caused an increase in the frequency of stroke occurrence. Moreover, we found that the G/G-T/T, G/G-C/C and G/C-C/C genotypes of c.-1493G >C - IDO1 (rs10089084) and c.975-7T > C- KAT2 (rs1480544) increased the risk of stroke about four times $(p=0.009), 18$ times $(p<0.001)$ and three times $(p<0.001)$, respectively. On the other hand, the $\mathrm{G} / \mathrm{C}-\mathrm{T} / \mathrm{C}$ genotype of the same polymorphism caused a drop in the risk just about fourteen times $(p<0.001)$. In the case of the c.-1849C > A - IDO1 (rs3824259) and c.804-7C > A - 
TPH1 (rs1799913) polymorphisms, the C/C-C/A and C/A-C/A combined polymorphisms were linked with a reduction of stroke risk about 20 times $(p=0.004)$ and 10 times $(p<0.001)$, respectively. The C/C-G/T, C/A-G/T and A/A-G/T combined genotypes of c.-1849C > A - IDO1 (rs3824259) and c.-844G $>\mathrm{T}-\mathrm{TPH} 2$ (rs4570625) caused a reduction of the stroke risk in the Polish population. However, the C/C-G/G, C/A-G/G and A/A-G/G genotypes of the same combined SNPs led to an increase of this risk about five times $(p=0.003), 66$ times $(p<0.001)$ and 10 times $(p<0.001)$, respectively. In the case of the next combined polymorphism, i.e., c. $-1849 \mathrm{C}>\mathrm{A}-\mathrm{IDO} 1$ (rs3824259) and c.803+221C $>\mathrm{A}$ - TPH1 (rs1800532), we confirmed that the C/C-C/A and A/A-C/A genotypes decreased the risk of stroke occurrence, while the $\mathrm{C} / \mathrm{A}-\mathrm{C} / \mathrm{C}$ and $\mathrm{A} / \mathrm{A}-\mathrm{A} / \mathrm{A}$ genotypes increased this risk in the studied population. Moreover, the frequency of the C/C-C/A genotype of c.-1849C > A - IDO1 (rs3824259) and c.-1449C >A - TPH2 (rs7963803) was decreased, while the C/A-C/C genotype was increased in the patients after a stroke as compared to the healthy volunteers. Additionally, we found that the only C/A-T/T genotype of the c.-1849C > A - IDO1 (rs3824259) and c.-173A > T - TPH1 (rs10488682) combined polymorphisms elevated the risk of stroke development. The C/C-T/T and C/A-T/T genotypes of c.-1849C > A - IDO1 (rs3824259) and c.-1668T > A - TPH1 (rs623580) were associated with a reduced risk of stroke, whereas the $\mathrm{C} / \mathrm{A}-\mathrm{T} / \mathrm{A}$ and $\mathrm{C} / \mathrm{A}-\mathrm{A} / \mathrm{A}$ genotypes caused an increase of the risk in the Polish population. Interestingly, the G/G-C/C, G/G-A/A as well as G/C-A/A of the c.-1493G > C - IDO1 (rs10089084) and c.804-7C > A - TPH1 (rs1799913) combined polymorphisms caused an increased frequency of stroke occurrence in the Polish population more than 20 times $(p=0.003)$, five times $(p<0.001)$, and nearly four times $(p<0.001)$, respectively. However, the G/C-C/A genotype of the same polymorphism combination was associated with increased stroke risk in this population by about eight times $(p<0.001)$. On the one hand, we observed that the G/C-G/G combined genotype of the c.-1493G $>$ C - IDO1 (rs10089084) and c.-844G > T - TPH2 (rs4570625) polymorphisms were associated with an increased risk of stroke. On the other hand, we found that the G/C-G/T and C/C-G/T genotypes of the same combined SNPs caused a reduction of this risk about six times $(p<0.001)$ and 17 times $(p<0.001)$, respectively. Interestingly, in the case of c.-1493G >C - IDO1 (rs10089084) and c.803+221C > A - TPH1 (rs1800532), we observed that the presence of the G/G-C/C combined genotype elevated the risk of stroke development more than 22 times $(p=0.003)$, whereas the $\mathrm{C} / \mathrm{C}-\mathrm{C} / \mathrm{A}$ genotype was associated with a nearly 18 -fold increase of the risk in the Polish population $(p<0.001)$. Moreover, an elevated risk of stroke for the G/G-C/G genotypes and a reduced risk for the $\mathrm{G} / \mathrm{C}-\mathrm{C} / \mathrm{A}$ and $\mathrm{C} / \mathrm{C}-\mathrm{C} / \mathrm{C}$ genotypes of the same polymorphisms were confirmed in our study. In our study, we confirmed the link between a reduced risk of stroke and the frequency of the C/C-C/C genotype of the c.-1493G $>C$ - IDO1 (rs10089084) and c.-1449C > A - TPH2 (rs7963803) polymorphisms. However, the G/G-C/C and G/C-C/C genotypes of the same polymorphism combination increased this risk in the studied polymorphism. The G/G-A/T and G/G-T/T genotypes of c.-1493G >C - IDO1 (rs10089084) and c.-173A > T - TPH1 (rs10488682) caused an increase of the risk of stroke, whereas the $\mathrm{C} / \mathrm{C}-\mathrm{A} / \mathrm{T}$ and $\mathrm{C} / \mathrm{C}-\mathrm{T} / \mathrm{T}$ genotypes of the same combined polymorphisms brought about a reduction of this risk. We found that the G/C-T/T, C/C-T/T and C/C-T/A genotypes of c.-1493G > C - IDO1 (rs10089084) and c.-1668T>A - TPH1 (rs623580) reduced the risk of stroke, whereas the $\mathrm{G} / \mathrm{G}-\mathrm{T} / \mathrm{A}$ genotype increased this risk. Moreover, the frequency of the G/G-C/A and G/A-C/A genotypes of the c. ${ }^{*} 456 \mathrm{G}>\mathrm{A}$ (rs10988134) - KAT1 and c.804-7C > A - TPH1 (rs1799913) combined polymorphisms was decreased in the patients after a stroke as compared to the controls by about 12 times $(p<0.001)$ and 25 times $(p=0.002)$, respectively. However, in the case of the same polymorphisms, the patients with stroke were characterized by an increased frequency of occurrence of the G/G-A/A, G/A-C/C and G/A-A/A genotypes. Moreover, the G/G-G/G combined genotypes of c. ${ }^{*} 456 \mathrm{G}>\mathrm{A}(\mathrm{rs} 10988134)-K A T 1$ and c.-844G $>\mathrm{T}-\mathrm{TPH} 2$ (rs4570625) caused a more than elevenfold increase of the risk in the Polish population $(p<0.001)$, whereas the G/G-G/T and G/A-G/T genotypes caused a reduction of stroke occurrence. We also confirmed that the G/G-C/A and G/A-C/A combined genotypes of c. ${ }^{*} 456 \mathrm{G}>\mathrm{A}(\mathrm{rs} 10988134)-\mathrm{KAT1}$ and c.803+221C > A - TPH1 (rs1800532) were related with a decreased risk of stroke, but the G/G-A/A and G/A-C/C combined genotypes of the same polymorphism increased this risk. The $\mathrm{G} / \mathrm{G}-\mathrm{C} / \mathrm{C}, \mathrm{G} / \mathrm{A}-\mathrm{C} / \mathrm{C}$ combined genotypes 
of c. ${ }^{*} 456 \mathrm{G}>\mathrm{A}(\mathrm{rs} 10988134)-\mathrm{KAT1}$ and c. $-1449 \mathrm{C}>\mathrm{A}-\mathrm{TPH} 2$ (rs7963803) were linked with elevated occurrence of stroke, while the G/G-C/A genotype of the same polymorphism combination decreased this risk more than thirty times $(p<0.001)$. Additionally, the presence of the G/G-T/T and G/A-T/T combined genotypes of the c. ${ }^{*} 456 \mathrm{G}>\mathrm{A}(\mathrm{rs} 10988134)-K A T 1$ and c.-1668T $>$ A - TPH1 (rs623580) polymorphisms reduced the risk of stroke development, while the G/G-T/A genotype increased this risk in the studied population. The T/T-A/A, C/C-C/C and C/C-A/A genotypes of c.975-7T > C- KAT2 (rs1480544) and c.804-7C > A - TPH1 (rs1799913) caused an increase of the risk of stroke. Interestingly, the presence of the T/T-G/G and C/C-G/G combined genotypes of the c.975-7T > C-KAT2 (rs1480544) and c.-844G $>\mathrm{T}-\mathrm{TPH} 2$ (rs4570625) polymorphisms elevated the risk of stroke development more than 30 times $(p=0.001)$. On the other hand, the T/T-G/T genotype of the same combined SNPs caused a decrease of this risk. Moreover, the T/C-C/A combined genotypes c.975-7T > C-KAT2 (rs1480544) and c.803+221C > A - TPH1 (rs1800532) caused a more than 20-fold reduction of the stroke risk in the Polish population $(p=0.001)$, whereas the $\mathrm{C} / \mathrm{C}-\mathrm{C} / \mathrm{C}$ genotype increased this risk about ten times $(p=0.001)$. The T/T-C/C and C/C-C/C genotypes of c.975-7T > C - KAT2 (rs1480544) and c.-1449C > A - TPH2 (rs7963803) caused an increase of the risk of DD by just about three times $(p=0.003)$ and 11 times $(p<0.001)$, respectively. However, the $\mathrm{T} / \mathrm{C}-\mathrm{C} / \mathrm{C}$ and $\mathrm{C} / \mathrm{C} / \mathrm{C} / \mathrm{A}$ genotypes of the same combined polymorphisms brought about a reduction of this risk by 16 times $(p<0.001)$ and 13 times $(p=0.014)$, respectively. The T/T-T/T, C/C-A/T, C/C-T/T combined genotypes of c.975-7T > C- KAT2 (rs1480544) and c.-173A > T - TPH1 (rs10488682) were linked with an increased risk of stroke occurrence, while the $\mathrm{T} / \mathrm{C}-\mathrm{T} / \mathrm{T}$ genotype of the same polymorphism combination decreased this risk. Moreover, we found that the T/T-T/A, C/C-T/A, C/C-A/A genotypes of c.975-7T > C- KAT2 (rs1480544) and c.-1668T > A - TPH1 (rs623580) increased the risk of stroke about threefold $(p=0.016)$, fourfold $(p<0.001)$ and 27-fold $(p<0.001)$, respectively. On the other hand, the T/C-T/T and T/C-T/A genotypes of the same combined SNPs caused a drop in stroke occurrence by more than 37 times and 15 times, respectively. No statistical correlation was found between combined genotypes of the c. ${ }^{*} 456 \mathrm{G}>\mathrm{A}(\mathrm{rs} 10988134)-$ KAT1 and c.-173A > T - TPH1 (rs10488682) polymorphisms and the development of stroke.

Table 4. Distribution of genotypes and alleles of c.804-7C > A - TPH1 (rs1799913), c.803+221C > A - TPH1 (rs1800532), c.-173A > T - TPH1 (rs10488682), c.-1668T > A - TPH1 (rs623580), c.-844G > T TPH2 (rs4570625), c.-1449C > A - TPH2 (rs7963803) c. ${ }^{*} 456 \mathrm{G}>\mathrm{A}$ of KAT1 (rs10988134), c.975-7T > C of AADAT (rs1480544), c.-1849C > A (rs3824259) and c.-1493G > C (rs10089084) of IDO1 and incidence of stroke.

\begin{tabular}{|c|c|c|c|c|c|c|}
\hline \multirow{2}{*}{ Genotype/Allele } & \multicolumn{2}{|c|}{ Control $(n=107)$} & \multicolumn{2}{|c|}{ Stroke $(n=107)$} & \multirow{2}{*}{ Crude OR $(95 \% \mathrm{CI})$} & \multirow{2}{*}{$p$} \\
\hline & Number & Frequency & Number & Frequency & & \\
\hline \multicolumn{7}{|c|}{ c.804-7C > A - TPH1 (rs1799913) } \\
\hline $\mathrm{C} / \mathrm{C}$ & 23 & 0.215 & 35 & 0.327 & $1.775(0.962-3.277)$ & 0.066 \\
\hline $\mathrm{C} / \mathrm{A}$ & 57 & 0.533 & 5 & 0.047 & $0.043(0.016-0.114)$ & $<0.001$ \\
\hline $\mathrm{A} / \mathrm{A}$ & 27 & 0.252 & 67 & 0.626 & $4.963(2.761-8.919)$ & $<0.001$ \\
\hline \multicolumn{7}{|l|}{$\chi^{2}=5.407 ; p=0.020$} \\
\hline $\mathrm{C}$ & 103 & 0.481 & 75 & 0.350 & $0.678(0.487-0.944)$ & 0.021 \\
\hline A & 111 & 0.519 & 139 & 0.650 & $1.475(1.060-2.054)$ & 0.021 \\
\hline \multicolumn{7}{|c|}{ c.803+221C > A - TPH1 (rs1800532) } \\
\hline $\mathrm{C} / \mathrm{C}$ & 23 & 0.215 & 41 & 0.383 & $2.269(1.240-4.150)$ & 0.008 \\
\hline $\mathrm{C} / \mathrm{A}$ & 83 & 0.776 & 48 & 0.449 & $0.235(0.130-0.426)$ & $<0.001$ \\
\hline $\mathrm{A} / \mathrm{A}$ & 1 & 0.009 & 18 & 0.168 & $\begin{array}{c}21.438 \\
(2.806-163.770)\end{array}$ & 0.003 \\
\hline \multicolumn{7}{|l|}{$\chi^{2}=0.014 ; p=0.907$} \\
\hline C & 129 & 0.602 & 130 & 0.607 & $1.028(0.651-1.623)$ & 0.907 \\
\hline A & 85 & 0.397 & 84 & 0.393 & $0.973(0.616-1.537)$ & 0.907 \\
\hline
\end{tabular}


Table 4. Cont.

\begin{tabular}{|c|c|c|c|c|c|c|}
\hline \multirow{2}{*}{ Genotype/Allele } & \multicolumn{2}{|c|}{ Control $(n=107)$} & \multicolumn{2}{|c|}{ Stroke $(n=107)$} & \multirow{2}{*}{ Crude OR $(95 \% \mathrm{CI})$} & \multirow{2}{*}{$p$} \\
\hline & Number & Frequency & Number & Frequency & & \\
\hline \multicolumn{7}{|c|}{ c. $-173 \mathrm{~A}>\mathrm{T}-\mathrm{TPH} 1$ (rs10488682) } \\
\hline $\mathrm{T} / \mathrm{T}$ & 57 & 0.533 & 64 & 0.598 & $1.306(0.759-2.245)$ & 0.335 \\
\hline $\mathrm{A} / \mathrm{T}$ & 47 & 0.439 & 40 & 0374 & $0.762(0.441-1.317)$ & 0.330 \\
\hline $\mathrm{A} / \mathrm{A}$ & 3 & 0.028 & 3 & 0.028 & $1.000(0.197-5.069)$ & 1.000 \\
\hline \multicolumn{7}{|l|}{$\chi^{2}=0.753 ; p=0.386$} \\
\hline $\mathrm{T}$ & 161 & 0.752 & 168 & 0.785 & $1.240(0.762-2.019)$ & 0.387 \\
\hline A & 53 & 0.248 & 46 & 0.215 & $0.806(0.495-1.313)$ & 0.387 \\
\hline \multicolumn{7}{|c|}{ c.-1668T > A - TPH1 (rs623580) } \\
\hline $\mathrm{T} / \mathrm{T}$ & 53 & 0.495 & 22 & 0.206 & $0.264(0.144-0.482)$ & $<0.001$ \\
\hline $\mathrm{T} / \mathrm{A}$ & 45 & 0.421 & 62 & 0.579 & $1.898(1.103-3.267)$ & 0.021 \\
\hline $\mathrm{A} / \mathrm{A}$ & 9 & 0.084 & 23 & 0.215 & $2.981(1.308-6.796)$ & 0.009 \\
\hline \multicolumn{7}{|l|}{$\chi^{2}=21,356 ; p<0.001$} \\
\hline $\mathrm{T}$ & 151 & 0.706 & 106 & 0.495 & $0.373(0.240-0.581)$ & $<0.001$ \\
\hline $\mathrm{A}$ & 63 & 0.294 & 108 & 0.505 & $2.681(1.722-4.173)$ & $<0.001$ \\
\hline \multicolumn{7}{|c|}{ c. $-844 \mathrm{G}>\mathrm{T}-\mathrm{TPH} 2(\mathrm{rs} 4570625)$} \\
\hline $\mathrm{G} / \mathrm{G}$ & 8 & 0.075 & 78 & 0.729 & $\begin{array}{c}33.284 \\
(14.411-76.874)\end{array}$ & $<0.001$ \\
\hline $\mathrm{G} / \mathrm{T}$ & 97 & 0.907 & 29 & 0.271 & $0.038(0.018-0.084)$ & $<0.001$ \\
\hline $\mathrm{T} / \mathrm{T}$ & 2 & 0.019 & 0 & 0 & - & - \\
\hline \multicolumn{7}{|l|}{$\chi^{2}=107.455 ; p<0.001$} \\
\hline G & 113 & 0.528 & 185 & 0.864 & $\begin{array}{c}32.746 \\
(14.191-75.563)\end{array}$ & $<0.001$ \\
\hline $\mathrm{T}$ & 101 & 0.472 & 29 & 0.136 & $0.031(0.013-0.071)$ & $<0.001$ \\
\hline \multicolumn{7}{|c|}{ c. $-1449 \mathrm{C}>\mathrm{A}-\mathrm{TPH} 2$ (rs7963803) } \\
\hline $\mathrm{C} / \mathrm{C}$ & 65 & 0.607 & 98 & 0.916 & $7.036(3.208-15.429)$ & $<0.001$ \\
\hline $\mathrm{C} / \mathrm{A}$ & 34 & 0.318 & 1 & 0.009 & $0.020(0.003-0.151)$ & $<0.001$ \\
\hline $\mathrm{A} / \mathrm{A}$ & 8 & 0.075 & 8 & 0.075 & $1.000(0.361-2.770)$ & 1.000 \\
\hline \multicolumn{7}{|l|}{$\chi^{2}=14.794 ; p<0.001$} \\
\hline C & 164 & 0.766 & 197 & 0.921 & $2.596(1.525-4.418)$ & $<0.001$ \\
\hline A & 50 & 0.234 & 17 & 0.079 & $0.385(0.226-0.656)$ & $<0.001$ \\
\hline \multicolumn{7}{|c|}{ c. ${ }^{*} 46 \mathrm{G}>\mathrm{A}-\mathrm{KAT1}(\mathrm{rs} 10988134)$} \\
\hline $\mathrm{A} / \mathrm{A}$ & 5 & 0.047 & 1 & 0.009 & $0.192(0.022-1.676)$ & 0.136 \\
\hline $\mathrm{A} / \mathrm{G}$ & 35 & 0.327 & 37 & 0.346 & $1.087(0.617-1.918)$ & 0.772 \\
\hline $\mathrm{G} / \mathrm{G}$ & 67 & 0.626 & 69 & 0.645 & $1.084(0.621-1.892)$ & 0.776 \\
\hline \multicolumn{7}{|l|}{$\chi^{2}=0.572 ; p=0.450$} \\
\hline A & 45 & 0.210 & 39 & 0.182 & $0.826(0.503-1.356)$ & 0.450 \\
\hline G & 169 & 0.790 & 175 & 0.818 & $1.210(0.737-1.987)$ & 0.450 \\
\hline \multicolumn{7}{|c|}{ c.975-7T > C - KAT2 (rs1480544) } \\
\hline $\mathrm{C} / \mathrm{C}$ & 29 & 0.271 & 72 & 0.673 & $5.533(3.076-9.954)$ & $<0.001$ \\
\hline $\mathrm{T} / \mathrm{C}$ & 59 & 0.551 & 4 & 0.037 & $0.032(0.011-0.092)$ & $<0.001$ \\
\hline $\mathrm{T} / \mathrm{T}$ & 19 & 0.178 & 31 & 0.290 & $1.889(0.988-3.613)$ & 0.054 \\
\hline \multicolumn{7}{|l|}{$\chi^{2}=6.986 ; p=0.008$} \\
\hline $\mathrm{C}$ & 117 & 0.547 & 148 & 0.692 & $1.576(1.119-2.219)$ & 0.009 \\
\hline $\mathrm{T}$ & 97 & 0.453 & 66 & 0.308 & $0.634(0.451-0.893)$ & 0.009 \\
\hline \multicolumn{7}{|c|}{ c. $-1849 \mathrm{C}>\mathrm{A}-\mathrm{IDO1}$ (rs3824259) } \\
\hline $\mathrm{C} / \mathrm{C}$ & 31 & 0.290 & 25 & 0.234 & $0.747(0.405-1.379)$ & 0.351 \\
\hline $\mathrm{C} / \mathrm{A}$ & 47 & 0.439 & 59 & 0.551 & $1.569(0.915-2.691)$ & 0.102 \\
\hline $\mathrm{A} / \mathrm{A}$ & 29 & 0.271 & 23 & 0.215 & $0.736(0.393-1.380)$ & 0.340 \\
\hline \multicolumn{7}{|l|}{$\chi^{2}=214.000 ; p=0.429$} \\
\hline $\mathrm{C}$ & 109 & 0.509 & 109 & 0.509 & $1.000(0.686-1.458)$ & 1.000 \\
\hline A & 105 & 0.491 & 105 & 0.491 & $1.000(0.686-1.458)$ & 1.000 \\
\hline
\end{tabular}


Table 4. Cont.

\begin{tabular}{|c|c|c|c|c|c|c|}
\hline \multirow{2}{*}{ Genotype/Allele } & \multicolumn{2}{|c|}{ Control $(n=107)$} & \multicolumn{2}{|c|}{ Stroke $(n=107)$} & \multirow{2}{*}{ Crude OR $(95 \% \mathrm{CI})$} & \multirow{2}{*}{$p$} \\
\hline & Number & Frequency & Number & Frequency & & \\
\hline \multicolumn{7}{|c|}{ c. $-1493 G$ > C - IDO1 (rs10089084) } \\
\hline $\mathrm{G} / \mathrm{G}$ & 12 & 0.112 & 44 & 0.411 & $5.529(2.709-11.284)$ & $<0.001$ \\
\hline $\mathrm{G} / \mathrm{C}$ & 55 & 0.514 & 54 & 0.504 & $0.963(0.564-1.646)$ & 0.891 \\
\hline $\mathrm{C} / \mathrm{C}$ & 40 & 0.374 & 9 & 0.084 & $0.154(0.070-0.338)$ & $<0.001$ \\
\hline \multicolumn{7}{|l|}{$\chi^{2}=40.577 ; p<0.001$} \\
\hline G & 79 & 0.369 & 142 & 0.664 & $4.016(2.487-6.484)$ & $<0.001$ \\
\hline $\mathrm{C}$ & 135 & 0.631 & 72 & 0.336 & $0.249(0.154-0.402)$ & $<0.001$ \\
\hline
\end{tabular}

\section{Discussion}

A growing body of evidence suggests that abnormal tryptophan metabolism may play a crucial role in stroke development. Our results presented in this paper confirmed this hypothesis. This is the first study to show that all chosen polymorphisms of the genes encoding enzymes of the TRYCATs pathway (i.e., tryptophan hydroxylases, kynurenine aminotransferases, indoleamine 2,3-dioxygenases) may modulate the risk of stroke occurrence.

Tryptophan hydroxylase, which exists in two isoforms: TPH1 and TPH2, is one of the key enzymes of tryptophan metabolism. Human TPH1 is located at chromosome 11p15.3-14, and comprises 11 exons, while the human TPH2 gene is located at chromosome 12q15 and comprises 11 exons. Both isoforms are highly homologous and exhibit $71 \%$ of amino acid identity [27]. TPH converts L-tryptophan into L-5-hydroxytryptophan (serotonin precursor) [28]. Thus, abnormal amounts or activity of this enzyme may cause deficiencies of neuroprotective compounds such as kynurenic acid, and consequently, lead to the development of several diseases, including stroke. In our study, we genotyped four polymorphisms of TPH1 and two SNPs of TPH2. One of them - c.804-7C > A TPH1 (rs1799913) - is localised at intron 7 and the polypyrimidine stretch immediately upstream of the $3^{\prime}$ acceptor splice site. This substitution of pyrimidine for purine in the polypyrimidine consensus sequence may decrease the fidelity of splicing. Indeed, sequencing of TPH1 cDNA revealed no evidence of abnormal splicing [29]. So far, studies showed that the SNP was linked with increased 5-hydroxy indole acetic acid concentrations in cerebrospinal fluid [30]. Thus far, this SNP was only investigated in affective disorders. Previous studies showed that the $\mathrm{C} / \mathrm{C}$ genotype of this SNP was associated with the development of depression [22,31]. By contrast, we found that the C/A genotype may elevate, while the A/A genotype of the same genotype may increase the risk of stroke occurrence. This disturbance may be a result of differences in the activation of the TRYCATs pathway during the development of depression and stroke. Moreover, the number of case and control groups in both studies differed. The next potentially functional TPH1 polymorphism in our study is the c.803 $+221 \mathrm{C}>$ A polymorphism of TPH1 (rs18005832). This SNP is localised at intron 7 in the potential GATA transcription factor-binding site, which allows the initiation of transcription. A previous study demonstrated that the polymorphism might be involved in the pathophysiology of affective disorders [22]. The A/A genotype may increase the risk of depression development in the Polish population. Similarly, in the case of the TPH1 polymorphism, we confirmed that the A/A genotype increased the risk of stroke. Moreover, the frequency of A allele was high in suicide attempters as compared to healthy volunteers in a Turkish population [32]. However, the same polymorphism was not associated with the occurrence of schizophrenia in Japanese populations [33]. Interestingly, this polymorphism was also linked with an elevated alcohol dependence risk in a Caucasian population, whereas the association was not of significance in Asian populations [34]. Another TPH1 polymorphism studied during this experiment was c.-173A > T (rs10488682). The SNP is localized in the promoter region of TPH1 and may reduce promoter activity, changing the transcription level of TPH1 [35]. So far, we have been the first to investigate that c.-173A > T SNP of TPH1 may contribute to the development of stroke. We found that the polymorphism was not associated with the occurrence 
of stroke. Likewise, the case-control study revealed no statistically significant association between TPH1 SNPs and progression of idiopathic scoliosis in an Eastern European population [36]. On the other hand, the A allele of the polymorphism was associated with a tendency to be resistant to brace treatment of adolescent idiopathic scoliosis in an Asian population [37]. Moreover, Wigner et al. [22] showed that the $\mathrm{T} / \mathrm{T}$ genotype caused an increase in depression risk.

The next studied polymorphism was c.-1668T > A SNP (rs623580). The SNP is localised in the exon 1c/intron 1 region and is within the $5^{\prime} \mathrm{UTR}$ region [38]. The T/T genotype of this polymorphism was associated with a decreased risk of depression, while the A/A genotype increased this risk [22]. Similarly, in our study, we confirmed that T/T increased the risk of stroke occurrence, and the A/A genotype elevated this risk as well. Moreover, Kwak et al. [39] found that this polymorphism was linked with the body mass index, a measure of obesity frequently related to MDD.

Besides the SNP localised in TPH1, we also studied TPH2 polymorphisms, and c.-844G $>$ T (rs4576025) was one of them. This polymorphism is associated with a change of DNA-protein interactions, ultimately affecting transcription of the $T P H 2$ gene. Indeed, the presence of the $\mathrm{T}$ allele may lead to a reduction of TPH2 promoter activity and may cause inhibition of serotonin synthesis [40-43]. Additionally, the SNP demonstrates a potential impact on the modulation of amygdala's response to emotional stimuli [44-46]. Interestingly, the amygdala's response may also be increased by the reduction of serotonin signals $[47,48]$. Thus, the SNP may modulate emotion signalling through impairment of the serotonin function. Previous studies showed that the G/G genotype of the polymorphism was associated with an increased risk of depression and suicidal attempts in depressed patients. Moreover, the heterozygote of this polymorphism was negatively correlated with depression occurrence [22]. Similarly, we found that the G/G homozygote was positively correlated with stroke occurrence, whereas the $\mathrm{G} / \mathrm{T}$ genotype caused a reduction of this risk.

Interestingly, stroke survivors were characterized by the occurrence of affective disorders both in the acute period and follow-ups, which may adversely impact rehabilitation and prognosis [49]. Thus, previous studies suggest that the TRYCATs pathway is involved in the pathophysiology of post-stroke anxiety $[50,51]$. Moreover, the $G$ allele of the TPH2 polymorphism was associated with the occurrence of post-stroke anxiety [52]. Likewise, our study confirmed that the G allele of this SNP caused an increase in the stroke risk. Furthermore, the SNP of the TPH2 gene was associated with the development of paranoid schizophrenia, multiple sclerosis, and panic disorders $[37,46,53]$. The second studied polymorphism of TPH2 was c.-1449C > A (rs7963803). Moreover, the C/C homozygote and $\mathrm{C}$ allele of this SNP decreased the risk of development of depressive disorders [22]. On the other hand, our study showed that this homozygote increased the risk of stroke occurrence, whereas the C/A heterozygote reduced this risk. Such disturbances may be a result of different bases for the development mechanism of both diseases or varied sizes of the studied groups.

Kynurenine aminotransferase is the next key enzyme of the TRYCATs pathway, described in this paper. KAT catalyses irreversible transamination of kynurenine acid in the brain and peripheral tissues [13,14]. Four isoforms of this enzyme have been described so far (KATI/glutamine transaminase $\mathrm{K}(\mathrm{GTK}) /$ cysteine conjugate beta-lyase (CCBL) 1, KATII/aminoadipate aminotransferase (AADAT), KAT III/CCBL2, and KAT IV/glutamicoxaloacetic transaminase (GOT) 2/mitochondrial aspartate aminotransferase (ASAT) [54]. However, we studied only two isoforms, i.e., KAT1 and KAT2. The gene encoding KAT1 is localized at chromosome 9q34.11; this enzyme limits the generation of kynurenic acid. We were the first to investigate the link between the c. ${ }^{*} 456 \mathrm{G}>\mathrm{A}$ (rs10988134) polymorphism of KAT1 and stroke occurrence. This SNP causes a transition in the $3^{\prime} \mathrm{UTR}$ region, which may affect KAT1 transcript stability [55]. To date, several transcript variants of KAT1, which are known to influence substrate specificity, have been described. We found no link between polymorphism occurrence and the risk of stroke. Interestingly, apart from our team, no one has been concerned with this polymorphism so far. KAT2 is another isoform of KAT presented in this paper. The gene of this enzyme is localized on chromosome 4q33, while the studied c.975-71T > C (rs1480544) polymorphism is found in putative exonic splicing silencers (ESSs). The SNP may cause quantitative changes in the production 
of canonical mRNAs and peptide generation, and, consequently, may contribute significantly to inter-individual phenotypic variability [56]. Moreover, the $C$ allele may cause an increase in mRNA expression and KATII protein production [57]. Thus, in our study, we found that the C/C genotype of this polymorphism caused an increase of the stroke risk, while the $\mathrm{C} / \mathrm{T}$ genotype decreased this risk. Additionally, a previous study, which had been conducted on a group of patients with human immunodeficiency virus (HIV), revealed that the $\mathrm{C}$ allele of this polymorphism could protect against psychopathological distress in controls, but not in HIV individuals [58].

Indoleamine 2,3-dioxygenase, which catalyses the first and rate-limiting step in the TRYCATs pathway leading to the initiation of $\mathrm{N}$-formylkynurenine, is yet another enzyme involved in the transformation of tryptophan. The gene encoding this enzyme is localized at chromosome 8 p11 $[12,59,60]$. Furthermore, an animal-based study confirmed that ischemia, which is observed during a stroke, increased the expression of tryptophan 2,3-dioxygenase (TDO) as compared to control animals. TDO may also catalyse the first and rate-limiting step of tryptophan degradation along the kynurenine pathway [15]. Interestingly, the TRYCATs pathway is closely linked with inflammatory modulation. IDO may be activated by pro-inflammatory cytokines, whereas anti-inflammatory cytokines may act as inhibitors of the enzyme $[16,17]$. Thus, an inflammatory response to an acute ischemic stroke may cause the activation of IDO, and, consequently, may lead to tryptophan depletion and increased generation of kynurenine [18]. Additionally, previous findings suggest that Interleukin 10 (IL-10) may reduce the capability of 5-TH synthesis in the brain, which is observed in the patients after a stroke $[19,20]$. Moreover, Ormstad et al. [21] revealed that high levels of interleukin $1 \beta$ are positively correlated with decreased bioavailability of TRP in the patients after an acute ischemic stroke. More details about the TRYCATs pathway were presented somewhere else [22]. In presented paper the both studied polymorphisms of IDO1, i.e., c.-1849C > A (rs3824259) and c.-1493G > C (rs10089084), are localized in $5^{\prime}$ region of the gene. A previous study showed no association between the two polymorphisms and IFN- $\alpha$-related depression [61]. Similarly, our team found no correlation between the frequency of the c.-1849C > A (rs3824259) polymorphism and the risk of stroke occurrence. On the other hand, in case of the second studied polymorphism, c. -1493G > C (rs10089084), we demonstrated that the G/G homozygote was associated with an increased risk of stroke development, whereas the $\mathrm{C} / \mathrm{C}$ genotype decreased this risk.

The findings of this work cast a new light on the pathogenesis of stroke; however, the present study had some potential limitations. The size of the studied group was relatively small and consequently of low power, which could lead to both false negative as well as false-positive findings. Thus, received results should be interpreted with caution and considered preliminary. Moreover, the studied population included patients and controls from Poland only, which reduces the possibility of confounding from ethnicity, so it does not permit any extrapolation of the results to other ethnic groups. Therefore, some additional larger case-control studies on different population groups and functional experiments are necessary before the final resolution about/findings as to the role of the TRYCATs pathway in the development of this disease. Moreover, the next limitations included no matching of the control group and patients in terms of vascular risk factors. In the future, the analysis should be extended to both the control group/patients with and without this risk. To conclude, the presented study showed a significant association between the tryptophan catabolism pathway and the occurrence of stroke, but the results obtained should be interpreted with great caution.

\section{Conclusions}

In the presented paper, we confirmed that the selected SNPs of the genes involved in the tryptophan catabolites pathway might influence the risk of depression occurrence. Among the studied SNPs, we found no link between the risk of stroke occurrence and only two polymorphisms, c.-173A $>\mathrm{T}$ - TPH1 (rs10488682) and c. ${ }^{*} 456 \mathrm{G}>\mathrm{A}-$ KAT1 (rs10988134). This study confirms the hypothesis that the TRYCATs pathway may be involved in the pathogenesis of stroke development. Thus, these polymorphisms may be considered independent markers of stroke. SNPs as biomarkers will allow 
the use of preventive measures in people at increased risk of stroke occurrence. Moreover, these markers will allow quick and new therapeutic strategies. In the future, further molecular studies of the underlying causes of stroke, including analyzing the level of expression of the studied genes, are necessary.

Supplementary Materials: The following are available online at http:/www.mdpi.com/2077-0383/8/12/2133/s1, Table S1: Haplotypes of TPH1, TPH2 and IDO1 and the risk of stroke. Table S2: Gene-gene interactions of studied polymorphisms and the risk of stroke.

Author Contributions: P.W., M.B., J.S.-B., and E.S. designed the study and wrote final version of manuscript; P.W., M.B. prepared all tables; P.W., N.C. and E.S. performed experiments; N.C. and E.S. contributed to analysis and interpretation of data, and assisted in the methodology and preparation of the manuscript; E.M. contributed biological material; T.S. and E.M. critically reviewed and edited the manuscript, and assisted in preparation of the work. All co-authors contributed to the creation of the manuscript, have read and approved the final version of the manuscript.

Funding: This work was supported by Grant 506/1136 from the University of Lodz.

Conflicts of Interest: The authors declare no competing financial and/or non-financial interests.

\section{References}

1. Mendis, S.; Lindholm, L.H.; Anderson, S.G.; Alwan, A.; Koju, R.; Onwubere, B.J.; Kayani, A.M.; Abeysinghe, N.; Duneas, A.; Tabagari, S.; et al. Total cardiovascular risk approach to improve the efficiency of cardiovascular prevention in resource constraint settings. J. Clin. Epidemiol. 2011, 64, 1451-1462. [CrossRef] [PubMed]

2. Organisation, W.H. Cerebrovascular Disorders (Offset Publications); World Health Organization: Geneva, Switzerland, 1978; ISBN 92-4-170043-2.

3. Benjamin, E.J.; Blaha, M.J.; Chiuve, S.E.; Cushman, M.; Das, S.R.; Deo, R.; de Ferranti, S.D.; Floyd, J.; Fornage, M.; Gillespie, C.; et al. Heart Disease and Stroke Statistics-2017 Update: A Report From the American Heart Association. Circulation 2017, 135, 146-603. [CrossRef] [PubMed]

4. Barker-Collo, S.; Bennett, D.A.; Krishnamurthi, R.V.; Parmar, P.; Feigin, V.L.; Naghavi, M.; Forouzanfar, M.H.; Johnson, C.O.; Nguyen, G.; Mensah, G.A.; et al. Sex Differences in Stroke Incidence, Prevalence, Mortality and Disability-Adjusted Life Years: Results from the Global Burden of Disease Study 2013. Neuroepidemiology 2015, 45, 203-214. [CrossRef] [PubMed]

5. Polyzos, K.A.; Ketelhuth, D.F. The role of the kynurenine pathway of tryptophan metabolism in cardiovascular disease. An emerging field. Hamostaseologie 2015, 35, 128-136. [CrossRef] [PubMed]

6. Mangge, H.; Stelzer, I.; Reininghaus, E.Z.; Weghuber, D.; Postolache, T.T.; Fuchs, D. Disturbed tryptophan metabolism in cardiovascular disease. Curr. Med. Chem. 2014, 21, 1931-1937. [CrossRef] [PubMed]

7. Stone, T.W.; Forrest, C.M.; Stoy, N.; Darlington, L.G. Involvement of kynurenines in Huntington's disease and stroke-induced brain damage. J. Neural Transm. 2012, 119, 261-274. [CrossRef] [PubMed]

8. Darlington, L.G.; Mackay, G.M.; Forrest, C.M.; Stoy, N.; George, C.; Stone, T.W. Altered kynurenine metabolism correlates with infarct volume in stroke. Eur. J. Neurosci. 2007, 26, 2211-2221. [CrossRef]

9. Slominski, A.; Semak, I.; Pisarchik, A.; Sweatman, T.; Szczesniewski, A.; Wortsman, J. Conversion of L-tryptophan to serotonin and melatonin in human melanoma cells. FEBS Lett. 2002, 511, 102-106. [CrossRef]

10. Swartz, K.J.; During, M.J.; Freese, A.; Beal, M.F. Cerebral synthesis and release of kynurenic acid: An endogenous antagonist of excitatory amino acid receptors. J. Neurosci. 1990, 10, 2965-2973. [CrossRef]

11. Mo, X.; Pi, L.; Yang, J.; Xiang, Z.; Tang, A. Serum indoleamine 2,3-dioxygenase and kynurenine aminotransferase enzyme activity in patients with ischemic stroke. J. Clin. Neurosci. 2014, 21, 482-486. [CrossRef]

12. Munn, D.H.; Mellor, A.L. Indoleamine 2,3 dioxygenase and metabolic control of immune responses. Trends Immunol. 2013, 34, 137-143. [CrossRef] [PubMed]

13. Kemp, J.A.; Foster, A.C.; Leeson, P.D.; Priestley, T.; Tridgett, R.; Iversen, L.L.; Woodruff, G.N. 7-Chlorokynurenic acid is a selective antagonist at the glycine modulatory site of the N-methyl-D-aspartate receptor complex. Proc. Natl. Acad. Sci. USA 1988, 85, 6547-6550. [CrossRef] [PubMed] 
14. Kessler, M.; Terramani, T.; Lynch, G.; Baudry, M. A glycine site associated with N-methyl-D-aspartic acid receptors: Characterization and identification of a new class of antagonists. J. Neurochem. 1989, 52, 1319-1328. [CrossRef] [PubMed]

15. Cuartero, M.I.; Ballesteros, I.; de la Parra, J.; Harkin, A.L.; Abautret-Daly, A.; Sherwin, E.; Fernández-Salguero, P.; Corbí, A.L.; Lizasoain, I.; Moro, M.A. L-kynurenine/aryl hydrocarbon receptor pathway mediates brain damage after experimental stroke. Circulation 2014, 130, 2040-2051. [CrossRef] [PubMed]

16. Fujigaki, H.; Saito, K.; Fujigaki, S.; Takemura, M.; Sudo, K.; Ishiguro, H.; Seishima, M. The signal transducer and activator of transcription $1 \alpha$ and interferon regulatory factor 1 are not essential for the induction of indoleamine 2,3-dioxygenase by lipopolysaccharide: Involvement of p38 mitogen-activated protein kinase and nuclear factor-kappaB pathways, and synergistic effect of several proinflammatory cytokines. J. Biochem. 2006, 139, 655-662. [CrossRef]

17. Wichers, M.C.; Koek, G.H.; Robaeys, G.; Verkerk, R.; Scharpé, S.; Maes, M. IDO and interferon-alpha-induced depressive symptoms: A shift in hypothesis from tryptophan depletion to neurotoxicity. Mol. Psychiatry 2005, 10, 538-544. [CrossRef]

18. Gulaj, E.; Pawlak, K.; Bien, B.; Pawlak, D. Kynurenine and its metabolites in Alzheimer's disease patients. Adv. Med. Sci. 2010, 55, 204-211. [CrossRef]

19. Levin, S.G.; Godukhin, O.V. Anti-inflammatory cytokines, TGF- $\beta 1$ and IL-10, exert anti-hypoxic action and abolish posthypoxic hyperexcitability in hippocampal slice neurons: Comparative aspects. Exp. Neurol 2011, 232, 329-332. [CrossRef]

20. Segev-Amzaleg, N.; Trudler, D.; Frenkel, D. Preconditioning to mild oxidative stress mediates astroglial neuroprotection in an IL-10-dependent manner. Brain Behav. Immun. 2013, 30, 176-185. [CrossRef]

21. Ormstad, H.; Verkerk, R.; Amthor, K.F.; Sandvik, L. Activation of the kynurenine pathway in the acute phase of stroke and its role in fatigue and depression following stroke. J. Mol. Neurosci. 2014, 54, 181-187. [CrossRef]

22. Wigner, P.; Czarny, P.; Synowiec, E.; Bijak, M.; Białek, K.; Talarowska, M.; Galecki, P.; Szemraj, J.; Sliwinski, T. Association between single nucleotide polymorphisms of TPH1 and TPH2 genes, and depressive disorders. J. Cell Mol. Med. 2018, 22, 1778-1791. [CrossRef] [PubMed]

23. Fernstrom, J.D. Role of precursor availability in control of monoamine biosynthesis in brain. Physiol. Rev. 1983, 63, 484-546. [CrossRef] [PubMed]

24. Monti, J.M. Serotonin control of sleep-wake behavior. Sleep Med. Rev. 2011, 15, 269-281. [CrossRef] [PubMed]

25. Eilertsen, G.; Ormstad, H.; Kirkevold, M. Experiences of poststroke fatigue: Qualitative meta-synthesis. J. Adv. Nurs. 2013, 69, 514-525. [CrossRef] [PubMed]

26. Sánchez-Martín, F.J.; Fernández-Salguero, P.M.; Merino, J.M. Aryl hydrocarbon receptor-dependent induction of apoptosis by 2,3,7,8-tetrachlorodibenzo-p-dioxin in cerebellar granule cells from mouse. J. Neurochem. 2011, 118, 153-162. [CrossRef] [PubMed]

27. Bennett, P.J.; McMahon, W.M.; Watabe, J.; Achilles, J.; Bacon, M.; Coon, H.; Grey, T.; Keller, T.; Tate, D.; Tcaciuc, I.; et al. Tryptophan hydroxylase polymorphisms in suicide victims. Psychiatric Genet. 2000, 10, 13-17. [CrossRef]

28. Mann, J.J.; Arango, V.; Underwood, M.D. Serotonin and suicidal behavior. Ann. N. Y. Acad. Sci. 1990, 600, 476-484. [CrossRef]

29. Nielsen, D.A.; Jenkins, G.L.; Stefanisko, K.M.; Jefferson, K.K.; Goldman, D. Sequence, splice site and population frequency distribution analyses of the polymorphic human tryptophan hydroxylase intron 7. Brain Res. Mol. Brain Res. 1997, 45, 145-148. [CrossRef]

30. Spurlock, D. Do no harm: Progression policies and high-stakes testing in nursing education. J. Nurs. Educ. 2006, 45, 297-302. [CrossRef]

31. Gizatullin, R.; Zaboli, G.; Jönsson, E.G.; Asberg, M.; Leopardi, R. Haplotype analysis reveals tryptophan hydroxylase (TPH) 1 gene variants associated with major depression. Biol. Psychiatry 2006, 59, 295-300. [CrossRef]

32. Beden, O.; Senol, E.; Atay, S.; Ak, H.; Altintoprak, A.E.; Kiyan, G.S.; Petin, B.; Yaman, U.; Aydin, H.H. TPH1 A218 allele is associated with suicidal behavior in Turkish population. Leg. Med. 2016, 21, 15-18. [CrossRef] [PubMed] 
33. Shiroiwa, K.; Hishimoto, A.; Mouri, K.; Fukutake, M.; Supriyanto, I.; Nishiguchi, N.; Shirakawa, O. Common genetic variations in TPH1/TPH2 genes are not associated with schizophrenia in Japanese population. Neurosci. Lett. 2010, 472, 194-198. [CrossRef]

34. Chen, D.; Liu, F.; Yang, C.; Liang, X.; Shang, Q.; He, W.; Wang, Z. Association between the TPH1 A218C polymorphism and risk of mood disorders and alcohol dependence: Evidence from the current studies. J. Affect. Disord. 2012, 138, 27-33. [CrossRef] [PubMed]

35. Côté, F.; Schussler, N.; Boularand, S.; Peirotes, A.; Thévenot, E.; Mallet, J.; Vodjdani, G. Involvement of NF-Y and Sp1 in basal and cAMP-stimulated transcriptional activation of the tryptophan hydroxylase (TPH ) gene in the pineal gland. J. Neurochem. 2002, 81, 673-685. [CrossRef] [PubMed]

36. Yablanski, V.; Nikolova, S.; Vlaev, E.; Savov, A.; Kremensky, I. Association Study between Promoter Polymorphism of TPH1 and Progression of Idiopathic Scoliosis. J. Biomark. 2016, 2016, 5318239. [CrossRef]

37. Xu, X.M.; Ding, M.; Pang, H.; Wang, B.J. TPH2 gene polymorphisms in the regulatory region are associated with paranoid schizophrenia in Northern Han Chinese. Genet. Mol. Res. 2014, 13, 1497-1507. [CrossRef]

38. Rotondo, A.; Schuebel, K.; Bergen, A.; Aragon, R.; Virkkunen, M.; Linnoila, M.; Goldman, D.; Nielsen, D. Identification of four variants in the tryptophan hydroxylase promoter and association to behavior. Mol. Psychiatry 1999, 4, 360-368. [CrossRef]

39. Kwak, S.H.; Park, B.L.; Kim, H.; German, M.S.; Go, M.J.; Jung, H.S.; Koo, B.K.; Cho, Y.M.; Choi, S.H.; Cho, Y.S.; et al. Association of variations in TPH1 and HTR2B with gestational weight gain and measures of obesity. Obesity 2012, 20, 233-238. [CrossRef]

40. Chen, G.L.; Vallender, E.J.; Miller, G.M. Functional characterization of the human TPH2 5' regulatory region: Untranslated region and polymorphisms modulate gene expression in vitro. Hum. Genet. 2008, 122, $645-657$. [CrossRef]

41. Scheuch, K.; Lautenschlager, M.; Grohmann, M.; Stahlberg, S.; Kirchheiner, J.; Zill, P.; Heinz, A.; Walther, D.J.; Priller, J. Characterization of a functional promoter polymorphism of the human tryptophan hydroxylase 2 gene in serotonergic raphe neurons. Biol. Psychiatry 2007, 62, 1288-1294. [CrossRef]

42. Reuter, M.; Ott, U.; Vaitl, D.; Hennig, J. Impaired executive control is associated with a variation in the promoter region of the tryptophan hydroxylase 2 gene. J. Cogn. Neurosci. 2007, 19, 401-408. [CrossRef] [PubMed]

43. Strobel, A.; Dreisbach, G.; Müller, J.; Goschke, T.; Brocke, B.; Lesch, K.P. Genetic variation of serotonin function and cognitive control. J. Cogn. Neurosci. 2007, 19, 1923-1931. [CrossRef]

44. Brown, S.M.; Peet, E.; Manuck, S.B.; Williamson, D.E.; Dahl, R.E.; Ferrell, R.E.; Hariri, A.R. A regulatory variant of the human tryptophan hydroxylase-2 gene biases amygdala reactivity. Mol. Psychiatry 2005, 10, 805, 884-888. [CrossRef] [PubMed]

45. Canli, T.; Congdon, E.; Gutknecht, L.; Constable, R.T.; Lesch, K.P. Amygdala responsiveness is modulated by tryptophan hydroxylase-2 gene variation. J. Neural Transm. 2005, 112, 1479-1485. [CrossRef] [PubMed]

46. Kim, Y.K.; Lee, H.J.; Yang, J.C.; Hwang, J.A.; Yoon, H.K. A tryptophan hydroxylase 2 gene polymorphism is associated with panic disorder. Behav. Genet. 2009, 39, 170-175. [CrossRef] [PubMed]

47. Cools, R.; Calder, A.J.; Lawrence, A.D.; Clark, L.; Bullmore, E.; Robbins, T.W. Individual differences in threat sensitivity predict serotonergic modulation of amygdala response to fearful faces. Psychopharmacology 2005, 180, 670-679. [CrossRef]

48. Milak, M.S.; Ogden, R.T.; Vinocur, D.N.; Van Heertum, R.L.; Cooper, T.B.; Mann, J.J.; Parsey, R.V. Effects of tryptophan depletion on the binding of [11C]-DASB to the serotonin transporter in baboons: Response to acute serotonin deficiency. Biol. Psychiatry 2005, 57, 102-106. [CrossRef]

49. Hackett, M.L.; Yapa, C.; Parag, V.; Anderson, C.S. Frequency of depression after stroke: A systematic review of observational studies. Stroke 2005, 36, 1330-1340. [CrossRef]

50. Bergersen, H.; Frøslie, K.F.; Stibrant Sunnerhagen, K.; Schanke, A.K. Anxiety, depression, and psychological well-being 2 to 5 years poststroke. J. Stroke Cerebrovasc. Dis. 2010, 19, 364-369. [CrossRef]

51. Morrison, V.; Pollard, B.; Johnston, M.; MacWalter, R. Anxiety and depression 3 years following stroke: Demographic, clinical, and psychological predictors. J. Psychosom. Res. 2005, 59, 209-213. [CrossRef]

52. Chi, S.; Teng, L.; Song, J.H.; Zhou, C.; Pan, W.H.; Zhao, R.L.; Zhang, C. Tryptophan hydroxylase 2 gene polymorphisms and poststroke anxiety disorders. J. Affect. Disord. 2013, 144, 179-182. [CrossRef] [PubMed] 
53. Natarajan, R.; Einarsdottir, E.; Riutta, A.; Hagman, S.; Raunio, M.; Mononen, N.; Lehtimäki, T.; Elovaara, I. Melatonin pathway genes are associated with progressive subtypes and disability status in multiple sclerosis among Finnish patients. J. Neuroimmunol. 2012, 250, 106-110. [CrossRef] [PubMed]

54. de Souza, F.R.; Fontes, F.L.; da Silva, T.A.; Coutinho, L.G.; Leib, S.L.; Agnez-Lima, L.F. Association of kynurenine aminotransferase II gene C401T polymorphism with immune response in patients with meningitis. BMC Med. Genet. 2011, 12, 51. [CrossRef] [PubMed]

55. Moore, L.E.; Boffetta, P.; Karami, S.; Brennan, P.; Stewart, P.S.; Hung, R.; Zaridze, D.; Matveev, V.; Janout, V.; Kollarova, H.; et al. Occupational trichloroethylene exposure and renal carcinoma risk: Evidence of genetic susceptibility by reductive metabolism gene variants. Cancer Res. 2010, 70, 6527-6536. [CrossRef] [PubMed]

56. Královicová, J.; Vorechovsky, I. Global control of aberrant splice-site activation by auxiliary splicing sequences: Evidence for a gradient in exon and intron definition. Nucleic Acids Res. 2007, 35, 6399-6413. [CrossRef] [PubMed]

57. Coutinho, L.G.; Christen, S.; Bellac, C.L.; Fontes, F.L.; Souza, F.R.; Grandgirard, D.; Leib, S.L.; Agnez-Lima, L.F. The kynurenine pathway is involved in bacterial meningitis. J. Neuroinflamm. 2014, 11, 169. [CrossRef] [PubMed]

58. Douet, V.; Tanizaki, N.; Franke, A.; Li, X.; Chang, L. Polymorphism of Kynurenine Pathway-Related Genes, Kynurenic Acid, and Psychopathological Symptoms in HIV. J Neuroimmune Pharm. 2016, 11, 549-561. [CrossRef]

59. Dai, W.; Gupta, S.L. Molecular cloning, sequencing and expression of human interferon-gamma-inducible indoleamine 2,3-dioxygenase cDNA. Biochem. Biophys. Res. Commun. 1990, 168, 1-8. [CrossRef]

60. Najfeld, V.; Menninger, J.; Muhleman, D.; Comings, D.E.; Gupta, S.L. Localization of indoleamine 2,3-dioxygenase gene (INDO) to chromosome 8p12->p11 by fluorescent in situ hybridization. Cytogenet. Cell Genet. 1993, 64, 231-232. [CrossRef]

61. Galvão-de Almeida, A.; Quarantini, L.C.; Sampaio, A.S.; Lyra, A.C.; Parise, C.L.; Paraná, R.; de Oliveira, I.R.; Koenen, K.C.; Miranda-Scippa, A.; Guindalini, C. Lack of association of indoleamine 2,3-dioxygenase polymorphisms with interferon-alpha-related depression in hepatitis C. Brain Behav. Immun. 2011, 25, 1491-1497. [CrossRef] 